\title{
THE U.S. ENVIRONMENTAL PROTECTION AGENCY'S WATER QUALITY TRADING POLICY: NEW OPPORTUNITIES FOR ENVIRONMENTAL ADVOCACY GROUPS?
}

\author{
Sean Blacklocke* \\ CDM Ireland \\ 87/89 Morehampton Road \\ Donnybrook, Dublin 4, Ireland \\ Ben Dziegielewski, $\mathrm{PhD}$ \\ Southern Illinois University \& International Water Resources Association \\ Carbondale, IL 62901-4516, USA
}

\begin{abstract}
Environmental non-profit organizations in the United States (U.S.) are in the early stages of reacting to a revolutionary water pollution control policy. In January 2003, the U.S. Environmental Protection Agency (EPA), with the support of the U.S. Department of Agriculture, announced its Water Quality Trading Policy (the Policy) encouraging the trading of surplus water pollutant reduction credits. In doing so, the federal government, in essence, created a mechanism for environmental non-profit organizations to reduce water pollution by paying directly for wastewater treatment plant upgrades and runoff best management practices. In addition to providing a review of the history of water quality trading in the U.S. and an analytical trading model, this paper presents the results of a survey that evaluates how conventional environmental advocacy groups throughout the nation perceive the Policy. Conclusions are to be drawn on these groups' awareness of the Policy, their stated or anticipated endorsement of trading between regulated entities, and their anticipated willingness and/or ability to purchase surplus water pollutant reduction credits themselves under a variety of alternative contractual arrangements.
\end{abstract}

\section{KEY WORDS}

Water quality trading, market-based incentives, water resources economics

\section{INTRODUCTION}

Environmental advocacy groups in the United States (U.S.) are beginning to react to a relatively significant and fundamental policy change related to how Americans can address water pollution in their rivers, lakes, and estuaries - The U.S. Environmental Protection Agency's (EPA) Water Quality Trading Policy. This revolutionary federal policy encouraging trading of surplus pollutant reduction credits, first introduced officially by the EPA under the Clinton Administration in 1996 and reintroduced in January 2003, is being promoted as a sometimes-appropriate means of achieving cleaner surface waters, cheaper and faster than the established conventional regulatory 
approaches prescribed in the Clean Water Act. In general, government, industry, and at least one major environmental advocacy group are supporting this Policy. It is thought that of interest to some at this point in the Policy's development may be some anecdotal and empirical evidence regarding the awareness and attitudes about the Policy among the larger population of environmental advocacy groups.

As such, presented here is a discussion of the major national environmental advocacy groups' initial reactions to the EPA's Water Quality Trading Policy and the results from a 2004 survey to measure the awareness of and attitudes concerning the Policy among the broader environmental non-profit community. For the benefit of environmental advocacy group leaders that are still weighing the plusses and minuses associated with supporting and utilizing the Policy, a technical methodology for incorporating surplus water pollutant reduction credits trading into the current EPA water pollution control regulatory framework is also presented in Appendix A. As it is realized that the concept and practice of trading surplus water pollutant reduction credits may be unfamiliar to many readers, a summary of the evolution and current status of both the concept as well as the Water Quality Trading Policy itself precedes the presentation of the survey results and technical methodology.

\section{THE POLICY}

On January 13, 2003, the EPA released its new Water Quality Trading Policy. In actuality, the Policy is a refinement of a 1996 Clinton Administration Policy spurn from its Reinventing Government Initiative. In simplest terms, the Policy encourages generators of wastewater discharges and runoff pollutants to exchange permit requirements or other pollutant reduction efforts when doing so will result in higher water quality and lower waste treatment costs. In addition, the Policy endorses the purchase and retirement of permit holders' pollutant allowances by environmental advocacy groups.

For over a decade now, the EPA has encouraged its state regulatory delegates to coordinate their water pollution control efforts at the watershed level and to experiment with market approaches to water quality management such as water quality trading. This is in contrast to the approach generally taken during the first two decades of the Clean Water Act's implementation, where pollution reduction targets were primarily based on discharge characterizations made nationally across industry types. As such, historically, pollution abatement expenditures have not been allocated in such a way as to precisely target the specific sources that actually contribute to a stream segment's ambient water quality standards violations. Furthermore, the ambient standards themselves have tended to be based on a water body's historic use rather than the highest valued water uses it can provide (e.g., drinking, swimming, fishing, waste assimilation, etc.).

Recent renewed efforts to reincorporate Total Maximum Daily Loads (TMDL) into watershed management activities have refocused pollution control efforts on the actual sources contributing to ambient standards violations. The ambient standards themselves 
(i.e., the pollutant levels associated with the TMDL's), however, are still typically only examined via Use Attainability Analysis (UAA), a fairly crude estimate of the economic implications of the ambient standards adjustments that effectively reclassify a water body for uses other than its current ones.

Incorporating a water quality trading strategy into the current EPA and state-delegated water pollution control regimes that govern the wasteloads and water quality standards of particular water bodies can be technically challenging, but as demonstrated in the EPA's Water Quality Trading Assessment Handbook published in November of 2004, doing so has been demonstrated to be a technical and legal reality given adequate monitoring and enforcement resources. In reality, much of the inertia associated with the evolution of the Policy seems to be more political than technical or legal. The reason may be obvious to some: The selling of surplus water pollutant reduction credits by 'polluters' amounts to essentially paying polluters not to pollute rather than having them pay for polluting consistent with the polluter pays principle.

\section{THE DEBATE}

The debate over whether government-allocated pollutant permits should be granted in the first place is not a new one. Such permits effectively legitimize the use of air and water waste assimilative capacities and do indeed make at least partially alienable the public right to the free use of truly pure air and water.

Also not new, perhaps surprisingly to some, is the debate over whether waste disposal entitlements, once allocated and regulated by pollution control authorities, should be transferable between entitlement holders and available for purchase by those seeking to eliminate such entitlements. In fact, among economists and legal scholars, such debates over how to address the overexploitation of open-access resources, such as air and water, have been going on for centuries. John Stuart Mill's 19th Century writings on political economy reference the very problem of increased scarcity of pure air and the likelihood that one day this scarcity might produce a marketable commodity.

More contemporary notable academics adhering strictly to the Chicago or New Haven Schools of economic and legal thought, respectively, have extensively developed the debate over the relative merits of marketable private rights versus inalienable public rights to air and water uses.

Scores of other scholars, those concerned in varying amounts with both wealth maximization and wealth distribution, have contributed much to the debate as well. One of these scholars, John Harkness Dales, actually proposed something similar to the EPA's Water Quality Trading Policy in his 1968 book Pollution, Property, \& Prices. Professor Dales started off by recognizing, "It is largely a waste of time for the pot to call the kettle black where pollution problems are concerned; everyone pollutes and everyone pays for not polluting." 
Dales noted that although pollution could be kept at bay by a number of techniques, the amount and the bearers of pollution control costs, and consequentially the expedience of water pollutant reductions and preventions, would differ greatly depending on which strategies were utilized. In his work, Dales theorized his way through different strategies - markets in pollution rights, polluted discharge taxes, and command and control regulations - and concluded that markets in pollution rights were "superior" in terms of practicality, efficiency, and fairness.

In his conclusions, Dales makes it clear that "Anyone, of course, should be allowed to buy Pollution Rights, even if they do not use them. Conservation groups might well want to buy up some rights merely in order to prevent their being used. In this way, at least part of the guerilla warfare between conservationists and polluters could be transferred into a civilized 'war with dollars'; both groups would, I think, learn something in the process."

For a variety of reasons, the EPA's Water Quality Trading Policy falls well short of what Dales had envisioned, as it is significantly constrained by command-and-control regulation and technical obstacles related to environmental forensics. And the Policy does not even approach the Chicago School strategy of creating full private property rights to the U.S.'s now publicly owned surface waters. In fact, free-market advocates hold pollutant trading in little higher regard than market socialism. Yet many of these scholars acknowledge that pollutant trading strategies are a positive first step in moving away from the current nominal inalienable rights doctrine and toward a more economically efficient regulatory regime. In fact, supporters of the Policy point out that according to the EPA, $\$ 658$ million to $\$ 7.5$ billion cost savings can be generated if it's fully implemented, and by design of the Policy, most of these freed financial resources would be directly reinvested in water pollutant reduction and prevention structures and practices, thereby expediting communities' water quality goals.

At least one major environmental advocacy group has publicly endorsed the Policy - the World Resources Institute. A study published by this Washington DC-based non-profit found that the cost of reducing loadings of nutrient pollutants in some Wisconsin waterways could be reduced by over $40 \%$ under a water quality trading strategy. The same study, Fertile Ground: Nutrient Trading's Potential to Cost-Effectively Improve Water Quality, showed that the costs of nutrient pollutant removals in some Michigan waterways could be reduced by over $80 \%$. The Institute has endorsed EPA's efforts to promote water quality trading as "sound environmental policy."

The EPA itself estimates that up to $80 \%$ cost reductions for nutrient pollutant removals on the Boise River in Idaho could materialize under its Water Quality Trading Policy. The EPA also reports that Connecticut's Nitrogen Exchange Program could potentially save \$200 million and expedite the achievement of water quality goals for Long Island Sound by 4 to 5 years. The Chesapeake Bay Program, a collaborative effort between the EPA and the States of Maryland, Virginia, Pennsylvania, and the District of Columbia, recently turned to nutrient trading to expedite the achievement of nutrient reduction goals 
in the Chesapeake Bay given that over two decades of regulatory efforts have failed to deliver the necessary reductions.

Several other similar examples of water quality trading from around the country are reported in the EPA's Draft Framework for Watershed-Based Trading published in 1996 and an EPA report published by Environomics on the topic in 1999.

Opposition to the Policy has predominantly come from environmental advocacy groups and has been generally related to distributions of pollutants and distributions of costs.

The Natural Resources Defense Council (NRDC), one of the few major national environmental advocacy groups that has publicly opposed the EPA's Water Quality Trading Policy, has voiced its concerns about pollutant distributions resulting from implementation of the Policy. NRDC points its constituents to the Policy's alleged propensity to induce toxic "hot spots" and buildups of persistent bioaccumulative pollutants like mercury in localized areas, specifically in waterways running through lowincome communities. In its official reaction to the EPA policy, NRDC stated, "The new trading scheme announced today by the Environmental Protection Agency allowing polluters to buy the right to increase their water pollutant discharges is illegal...Poor communities, disadvantaged communities, and minority communities will bear the brunt of this misguided policy."

While EPA acknowledges a general lack of current data on mixing zones (the immediate areas where discharges entering receiving waters have the potential to create toxic "hot spots"), Policy proponents point out that EPA does address these concerns. EPA's Policy states, "EPA does not support any use of credits or trading activity that would cause an impairment of existing or designated uses, adversely affect water quality at an intake for drinking water or that would exceed a cap established by a total maximum daily load."

With respect to persistent bioaccumulative pollutants, EPA's Policy states "EPA does not currently support trading of pollutants considered by EPA to be persistent bioaccumulative toxics (PBTs)."

Proponents of the Policy note that even if despite precautions, "hot spots" or PBTs somehow became occasional occurrences associated with the Policy, the idea that they would disproportionately and negatively impact "poor" or "minority" communities is unsubstantiated. They suggest that the NRDC is improperly interpreting studies analyzing the environmental justice implications of air emissions trading programs, such as one done a few years ago by Lily N. Chinn. Chinn did indeed find that "... if the marginal cost of pollution is correlated with race/or income, then pollution markets would lead to disparate impacts." Chinn, however, does conclude that this has not been demonstrated to be the case.

Regardless, according to Policy proponents, under a water quality trading strategy, dischargers, whether located in predominantly rich or poor or black or white areas, are 
collectively seeking to meet an ambient water quality standard for a particular pollutant, or in essence seeking to stay under a pollutant cap. They argue that these dischargers would be enabled by the Policy's flexibility to trade reduction requirements, not be further constrained by it.

They argue further that communities do not systematically become burdened with excessive human and ecological heath risks as a result of water quality trading, and that no water quality standards are lowered due to trading. According to Policy proponents, the existing risks inherent in the current exclusively regulatory regime are, in fact, lowered more expeditiously under the EPA Water Quality Trading Policy.

In its official position on "pollution trading" posted on its web page, the Sierra Club states that it "...opposes use of trading". In a publication entitled The Bush Administration's Record on the 30th Anniversary of the Clean Water Act, the Sierra Club states about the Policy (as it was proposed during a comment period in 2003), "Environmentalists have opposed this initiative, which is not permitted under the Clean Water Act...Currently, the draft policy does not require the trading partners to finance the program, so the regulatory burden would ultimately fall upon the taxpayer."

The Sierra Club raises the point with which Professor Dales and so many others have long been concerned. Who pays?

At the margins, the U.S. taxpayer indeed pays the cost of the Policy initiative, including $\$ 800,000$ EPA has made available to 10 pilot trading projects throughout the country. But Policy proponents note that at the same margins, that $\$ 800,000$ is devoted towards allowing the taxpayer to better realize the $\$ 658$ million to $\$ 7.5$ billion cost savings and expedited water quality improvements associated with full implementation of the Water Quality Trading Policy.

Indeed, given any EPA spending program, "the regulatory burden would ultimately fall upon the taxpayer." But under a national water quality trading strategy, proponents of the Policy argue, the burden would be directly alleviated through municipal and state tax revenue savings in the provision of public utilities, such as sewer services and storm water controls. And, indirectly, the financial burden to taxpaying consumers would be alleviated by lower prices for some private goods and services.

A Harvard Environmental Law Review article by Jonathan Remy Nash analyses this very conflict between tradable pollutant permit strategies and the "polluter pays" principle. Nash explains that "the core of this principle stems from the fundamental, logical, and fair proposition that those who generate pollution, not the government, should bear pollution costs."

There is little disagreement among academics on this point. Those advocating inalienable public rights to surface water uses agree in principle with those advocating fully alienable private property rights to surface water uses - polluters should pay 
precisely the costs of their pollution. The former group seeks to make polluters pay through regulatory controls that propose to internalize these costs, while the latter group seeks payment in the marketplace or at common law for accepting or enduring the pollution damages.

Proponents of the EPA Policy note that in the current U.S. command-and-control regulatory regime, with or without pollutant trading arrangements, polluters do not pay the full costs that are associated with their pollution. Under strictly command-andcontrol regulation, pollution control expenditures are already highly subsidized by taxpayers. Taxpayers also pay for the administration of the regulatory controls, controls that in no way precisely internalize pollution costs on polluters. And depending on the substitutability of any given polluter's good or service, some amount of the cost of pollution control is undoubtedly passed along to the consumer via pricing.

Under pollutant trading strategies retrofitted for the command-and-control regime, in this case the EPA's Water Quality Trading Policy, polluters enjoy an additional subsidy by having their existing pollutant load allocations "grandfathered" under the Policy (e.g., the loads under their existing wastewater discharge permits). By making this allocation transferable, the taxpayer essentially awards existing polluters with a sellable commodity, albeit a highly regulated one.

But either way, as critics of conventional regulatory water pollution control point out, the largest polluters do not pay the full cost associated with their pollution. In fact, in his conclusions, Nash acknowledges, "Many existing regulatory regimes may be even more at odds with the polluter pays principle than a tradable pollution allowance regime."

The debate over the principal and practice of trading surplus pollutant reduction credits presented above is obviously between relatively well-informed parties. It is thought, however, that the awareness and attitudes among U.S. environmental advocacy groups working at the watershed level, outside the Washington, D.C. Beltway, might also be of some interest now that the Policy is recognized and is being experimented with throughout the country. The proceeding section is a discussion of the findings of a survey aimed at soliciting this very type of information. No similar effort is known that predates this study.

\section{AWARENESS AND ATTITUDES AMONG ADVOCACY GROUPS}

In May of 2004, a mail survey of 333 U.S. environmental advocacy groups, in particular those that are members of an umbrella group in Washington, DC known as the Clean Water Network, was conducted. At the time of the survey, there were over 1000 member organizations in the Clean Water Network. The 333 sampled entities were selected exclusively on the basis of the availability of their contact details at the Guidestar web site, an online database of U.S. nonprofit organizations. 
Measured in the survey were the awareness of and attitudes about the EPA's Water Quality Trading Policy among these organizations. There were a total of 51 respondents. The results of the survey are presented in Table 1 below.

Table 1 - Results of 2004 Survey to Assess Awareness and Attitudes about the U.S. Environmental Protection Agency's Water Quality Trading Policy

\begin{tabular}{|c|c|c|c|c|}
\hline SURVEY QUESTIONS & YES & NO & $\mathbf{N} / \mathbf{A}$ & N/R \\
\hline $\begin{array}{l}\text { Prior to receipt of this survey, was your organization } \\
\text { aware of the United States Environmental Protection } \\
\text { Agency’s Water Quality Trading Policy? }\end{array}$ & $61 \%$ & $37 \%$ & $0 \%$ & $2 \%$ \\
\hline $\begin{array}{l}\text { If your organization was aware of the Policy, have you } \\
\text { made a public endorsement of the Policy? }\end{array}$ & $4 \%$ & $59 \%$ & $27 \%$ & $10 \%$ \\
\hline $\begin{array}{l}\text { If your organization was aware of the Policy, have you } \\
\text { publicly opposed the Policy? }\end{array}$ & $8 \%$ & $55 \%$ & $27 \%$ & $10 \%$ \\
\hline $\begin{array}{l}\text { If your organization was aware of the Policy and has } \\
\text { released no public statements endorsing or opposing it, is } \\
\text { this due in part to uncertainty regarding the Policy's } \\
\text { implications? }\end{array}$ & $33 \%$ & $18 \%$ & $39 \%$ & $10 \%$ \\
\hline $\begin{array}{l}\text { Given your organization's current knowledge concerning } \\
\text { the Policy, do you anticipate your stated or effective } \\
\text { support in the implementation of the Policy? }\end{array}$ & $6 \%$ & $61 \%$ & $22 \%$ & $12 \%$ \\
\hline $\begin{array}{l}\text { Given your organization's current knowledge concerning } \\
\text { the Policy, do you anticipate your organizations stated or } \\
\text { effective opposition to the implementation of the Policy? }\end{array}$ & $25 \%$ & $37 \%$ & $22 \%$ & $16 \%$ \\
\hline $\begin{array}{l}\text { Given your organization's current knowledge concerning } \\
\text { the Policy, do you foresee Policy implications related to } \\
\text { environmental justice serving as impediments to your } \\
\text { ultimate stated or effective endorsement of the Policy? }\end{array}$ & $43 \%$ & $18 \%$ & $29 \%$ & $10 \%$ \\
\hline $\begin{array}{l}\text { Given your organization's current knowledge concerning } \\
\text { the Policy, do you foresee Policy implications related to } \\
\text { pollutant "hot spots" serving as impediments to your } \\
\text { ultimate stated or effective endorsement of the Policy? }\end{array}$ & $55 \%$ & $16 \%$ & $24 \%$ & $6 \%$ \\
\hline $\begin{array}{l}\text { Given your organization's current knowledge concerning } \\
\text { the Policy, do you anticipate utilizing the Policy to } \\
\text { purchase surplus pollutant reduction credits for retirement } \\
\text { (i.e., to achieve water quality in excess of ambient water } \\
\text { quality standards) }\end{array}$ & $2 \%$ & $67 \%$ & $20 \%$ & $12 \%$ \\
\hline $\begin{array}{l}\text { Given your organization's current knowledge concerning } \\
\text { the Policy, do you anticipate utilizing the Policy to } \\
\text { purchase surplus pollutant reduction credits for resale } \\
\text { (i.e., to influence which dischargers utilize a stream's } \\
\text { assimilative capacity in compliance with ambient water } \\
\text { quality standards)? }\end{array}$ & $0 \%$ & $73 \%$ & $18 \%$ & $10 \%$ \\
\hline
\end{tabular}


The results presented in Table 1 indicate that while 61 percent of respondents were familiar with the Policy, only a small number of organizations had publicly expressed either their support or opposition (i.e., four and eight percent, respectively). Nearly onethird of those familiar with the policy made no statements because of their uncertainty about the Policy's implications. As was suspected, more than one-third of respondents $(37 \%)$ were unfamiliar with the Policy.

Based on their current knowledge concerning the Policy, the majority of respondents (61 percent) do not anticipate supporting the implementation of the Policy and 37 percent anticipate opposing its implementation. Two reasons for objections, namely environmental justice issues and pollution "hot spots", were marked by 43 percent and 55 percent of the respondents, respectively. Only one respondent indicated an intention to purchase surplus pollutant reduction credits for retirement in the future, and no respondents had plans to purchase and resell credits.

In reviewing the results of the survey presented above in conjunction with the "openended" comments that were submitted with these categorical responses, however, it is clear that many groups are still open to learning more about the potential opportunities the Policy may afford them and their constituents. For the benefit of those environmental advocacy group leaders, Appendix A is a framework detailing the type of modeling and analyses that might be requested of the EPA or its state delegates to facilitate environmental advocacy group's efficient purchase of surplus pollutant reduction credits in watersheds.

\section{CONCLUSIONS}

As is clear in the preceeding discussion of the debate over the relative merits of inalienable rights to pollutant-free waterways and tradeable government-allocated surplus pollutant reduction credits, and more specifically EPA's Water Quality Trading Policy, there is no consensus among relatively well-informed parties on this issue and this Policy. There continues to be debate over legal and technical aspects of the Policy, although a number of successful pilot projects (highlighted in the publication by Environomics and ohters) has demonstrated that political considerations remain the only real significant barriers to more widespread acceptance and implementation of the Policy.

In considering the results of the survey, it is arguably reasonable to believe that one day environmental advocacy groups will buy and retire (or perhaps even resell) surplus water pollutant reduction credits in U.S. watersheds. There is, in fact, a precedent for this type of environmental non-profit activity in the actions of organisations such as the Nature Conservancy in its purchasing of alienable property rights to land. While such an action by an enviornmental advocacy group to purchase surplus pollutant reduction credits would indeed be in part a symbolic relinquishment of the inalienable rights doctrine that governs U.S. waterways (albeit only nominally), it might also, in the words of John Harkness Dales, initate a more civilized war with dollars in U.S. watersheds, and begin to ease the sometimes less civilized, less efficient war of words inside the D.C. Beltway. 


\section{APPENDIX A. FRAMEWORK FOR ENVIRONMENTAL ADVOCACY GROUPS' PURCHASE OF SURPLUS POLLUTANT REDUCTION CREDITS}

The following is a comprehensive step-wise analytical framework for the facilitation of the purchase of surplus water pollutant reduction credits by environmental advocacy groups in the U.S. The three-part, watershed-based approach includes water quality analysis, economic analysis, and facilitated trading of surplus water pollutant reduction credits. This approach conforms to all existing Clean Water Act regulations.

\section{Water Quality Analysis}

Complete water quality modeling of current regulatory requirements for reductions in phosphorous, nitrogen, fecal coliform bacteria, ultimate oxygen demand (biological oxygen demand and ammonia), or other relevant pollutant (i.e. the reduction necessary to avoid exceeding the total maximum daily pollutant load (TMDL) for these pollutants at any determined critical stream segment under the determined critical environmental conditions $\left.\left(\mathrm{R}_{\mathrm{TMDLp}}\right)\right)$.

The required total pollutant reduction at the TMDL stream segment $\left(\mathrm{R}_{\mathrm{TMDLp}}\right)$ is a function of each source's relative impact on the TMDL stream segment $(\alpha)$. It is the sum of each pollutant sources' (i) required pollutant reduction (R) at each increment (j) under critical stream flow (f), stream temperature (t), and atmospheric conditions (a).

$\mathrm{R}_{\mathrm{TMDLp}}=f(\alpha, \mathrm{i}, \mathrm{j}, \mathrm{R}, \mathrm{f}, \mathrm{t}, \mathrm{a})$

Model to determine each identifiable and quantifiable pollutant source's relative pollutant impacts on the TMDL stream segment (i.e. determine $\alpha$ for all i).

The pollutant sources affecting any TMDL stream segment under critical environmental conditions can be point water pollutant sources (psw) such as wastewater discharge pipes, nonpoint water pollutant sources (npsw) such as agricultural land, point air pollutant sources (psa) such as smokestacks, and nonpoint air pollutant sources (npsa) such as automobile tailpipes.

$\mathrm{i}=$ psw, npsw, psa, npsa

\section{Economic Analysis}

Identify the pollutant sources' respective potential pollutant reductions at any determined critical stream segment $(R)$ and their coinciding discounted marginal costs $(\mathrm{mc})$ for increments of employment of additional pollutant abatement technologies (j).

Identify the combination of pollutant sources and respective pollutant reductions $\left(\mathrm{R}_{\mathrm{ij}}{ }^{*}\right)$ that minimize the total cost of achieving the reduction necessary at any determined critical stream segment to avoid exceeding the established total maximum daily load for these regulated pollutants. 


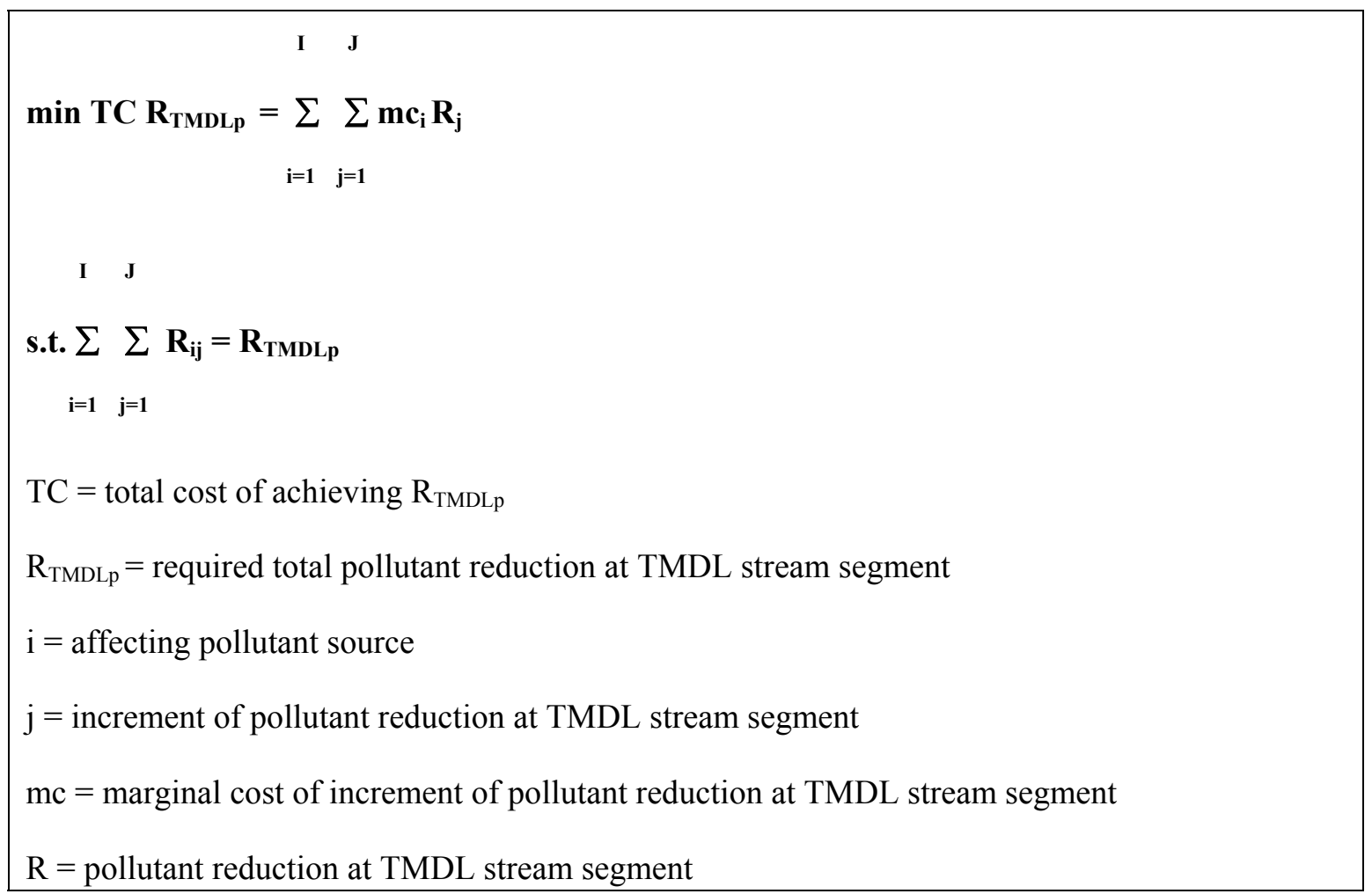

In other words, determine the optimal level of pollutant reduction among sources $\left(\mathrm{R}_{\mathrm{ij}}{ }^{*}\right)$ and the marginal cost at each sources' employed increment of additional pollutant abatement technology ( $\mathrm{mc}^{*}$ ), and solve for the constrained minimum total cost of achieving $\mathrm{R}_{\text {TMDLp. }}$.

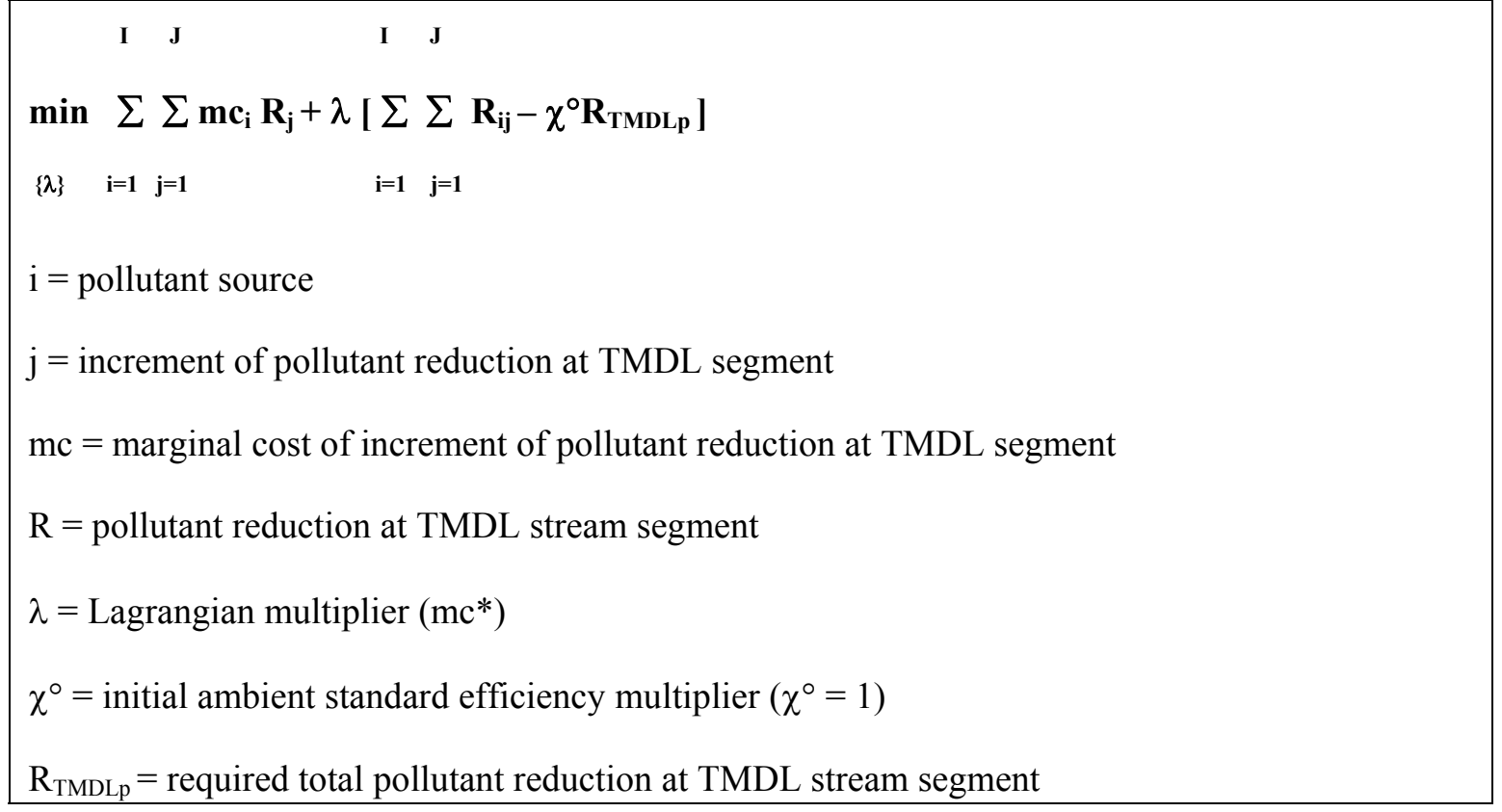


Calculate the total cost of achieving $\mathrm{R}_{\text {TMDLp }}$ for each pollutant under the established regulatory requirement and compare the regulatory allocation of pollutant reduction requirements among sources with the calculated optimal pollutant reduction for each source.

Identify and categorize the existing and potential water users (n) projected to still be affected by pollutants subsequent to attainment of $\mathrm{R}_{\mathrm{TMDLp}}$.

Identify and characterize the marginal benefits $(\mathrm{mb})$ among all identified water user categories at increments beyond $\mathrm{R}_{\mathrm{TMDLp}}$ to the point where the affecting pollutant's total maximum daily load is zero (OTMDLp).

Convert the characterized marginal benefits among all identified water user categories at each increment of marginal reduction to dollars and discount for present values.

Calculate the total dollar benefits for all identified water user categories of exceeding $\mathrm{R}_{\mathrm{TMDLp}}$ (exceeding the water quality standard) to the point where the affecting pollutant's total maximum daily load is zero.

TB OTMDLp $=\sum \sum \mathbf{m b}_{\mathbf{n}} \mathbf{R}_{\mathbf{j}}$
TB = total benefit of achieving $0 \mathrm{TMDL}_{\mathrm{p}}$
OTMDLp = necessary pollutant reduction at TMDL stream segment for TMDLp $=0$
$\mathrm{n}=$ existing and new affected water users, including new pollutant sources
$\mathrm{j}=$ increment of pollutant reduction at TMDL stream segment
mb = marginal benefit of increment of pollutant reduction at TMDL stream segment
$\mathrm{R}=$ pollutant reduction at TMDL stream segment

\section{Facilitated Trading}

Typically in the TMDL process, the regulatory authority will reallocate existing estimated loadings to sources, including those not currently subject to regulation under 40 CFR Part 122 and 40 CFR Part 412, often imparting uniform percentage pollutant reduction requirements necessary to meet $R_{T M D L p}$. 
Contact pollutant sources that are estimated to mutually benefit from exchanging pollutant reduction requirements with other sources and facilitate cost-savings trades in cooperation with the regulatory authority.

Upon trading, model runs are necessary to ensure the more cost-effective allocation of pollutant reduction requirements results in a total reduction that is equal to (or greater than) the current regulatory prescribed $\mathrm{R}_{\mathrm{TMDLp}}$.

Contact representative organizations of water user categories, including environmental advocacy groups, that are estimated to net out present value benefits from unilaterally or jointly financing pollutant reductions at identified sources. Facilitate contracts for temporal pollutant reductions between existing compliant pollutant sources and existing and new water user organizations, including new pollutant sources.

Model any proposed marginal pollutant reduction and pollutant reduction requirement reallocation to determine the extent to which the more marginally efficient water quality standard results in a total reduction that is greater than the regulatory prescribed $\mathrm{R}_{\text {TMDLp }}$. In other words, adjust the initial efficiency multiplier $\left(\chi^{1}\right)$ and remodel for $\mathrm{mc}^{*}$ and $\mathrm{R}_{\mathrm{ij}}{ }^{*}$.

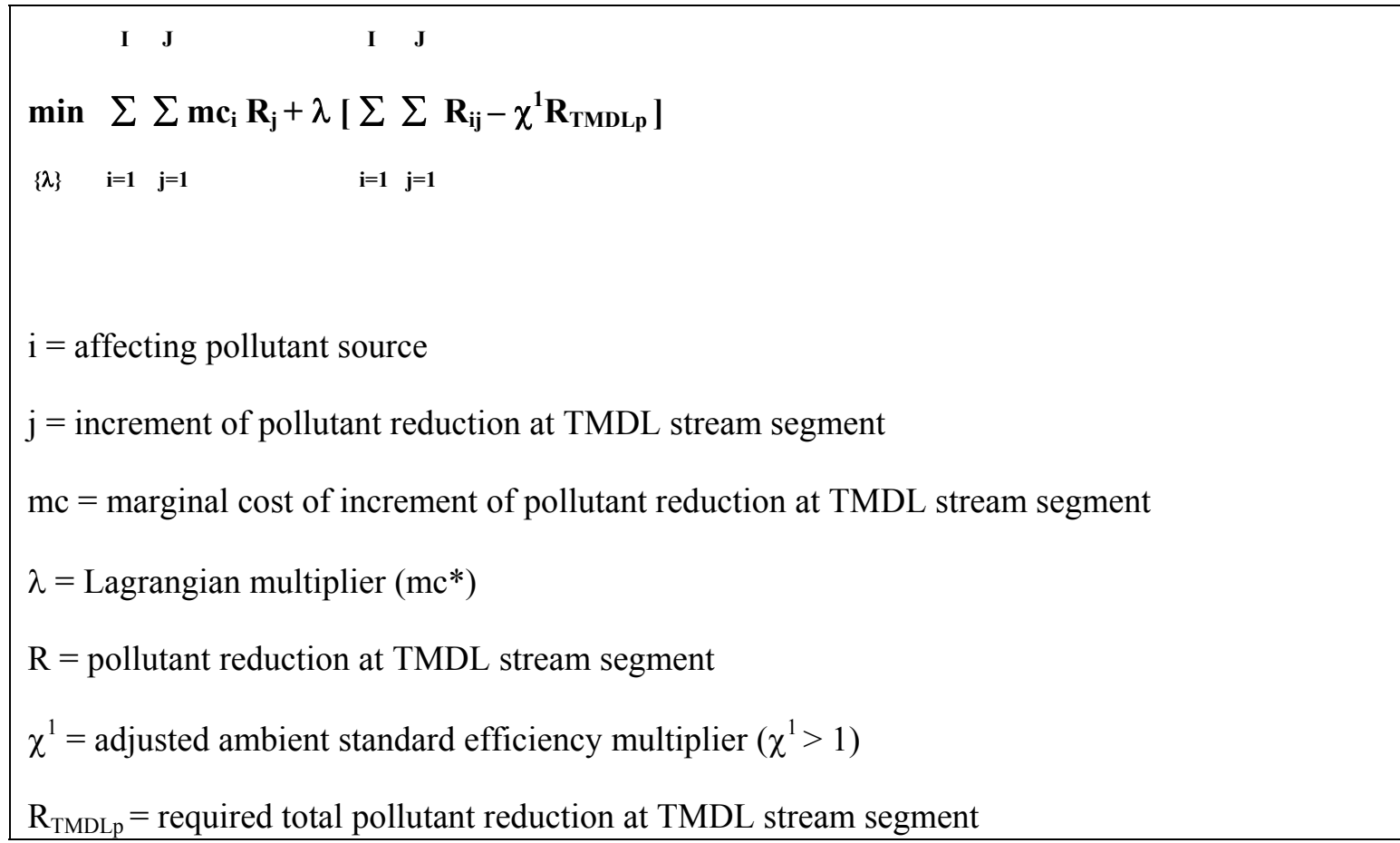

Remodel upon determination or refinement of any model input due to trading or improved analyses and make information available to all stakeholders, including environmental advocacy groups. 


\section{ACKNOWLEDGMENTS}

The authors wish to thank Bruce Yandle, David Batchelor, and Harry Zhang for their comments on earlier drafts of this paper and Tom Bic for his assistance with the survey. All opinions and any errors are attributable exclusively to the authors.

\section{REFERENCES}

Clean Water Network web site (2003) http://www.cwn.org.

Chinn, L.N. (1999) Can the market be fair and efficient? An environmental justice critique of emissions trading. 26 Ecology Law Quarterly 80.

Dales, J.H. (1968) Pollution, property \& prices: An essay in policy-making and economics. University of Toronto Press.

Environomics (1999) A Summary of U.S. Effluent Trading and Offset Projects. Prepared for the U.S. Environmental Protection Agency.

Faeth, P. (2000) Fertile Ground: Nutrient Trading's Potential to Cost-Effectively Improve Water Quality. World Resources Institute. Washington, DC.

Guidestar web site (2004) http://www.guidestar.org.

Nash, J.R. (2000) Too much market? Conflict between tradeable pollution allowances and the 'polluter pays' principle. Harvard Environmental Law Review, 24.

Natural Resources Defense Council web site (2003) http://www.nrdc.org.

Sierra Club web site (2003) http://www.sierraclub.org.

U.S. Environmental Protection Agency (1996) Draft Frameworkfor Watershed-Based Trading; EPA 800-R-96-001; Washington, DC.

U.S. Environmental Protection Agency (2004) Water Quality Trading Assessment Handbook: Can Water Quality Trading Advance Your Watershed's Goals? EPA 841-B-04-001; Washington, DC.

U.S. Environmental Protection Agency web site (2004) http://www.epa.gov. 